\title{
Letramento digital em um curso de formação continuada de professores de língua inglesa
}

\section{Eliane Carolina de Oliveira}

Professora Doutora do Departamento de Linguas

e Literaturas Estrangeiras da Faculdade de Letras

da UFG - Universidade Federal de Goiás; Goiânia;

Goiás; Brasil.

ecaol2@gmail.com

Resumo: Neste artigo discutimos aspectos referentes ao letramento digital de um grupo de professores de inglês participantes de um curso de formacão continuada. Embasados em trabalhos sobre letramento e letramento digital (BUZATO, 2001, 2006; SOARES, 2002, 2009; WARSCHAUER, 2011) apresentamos dados analisados via questionários, produções dos participantes e percepções da formadora os quais revelam que as experiências de letramento digital desse grupo aconteceram de forma natural, não pré-estabelecida, frequente, via input e output e intensamente colaborativas. Percebeuse também que a característica inovadora das aulas executadas via instrumentos tecnológicos digitais provocaram mudança de hábitos nesses professores em níveis tecnológico e organizacional.

Palavras-chave: Letramento; Letramento Digital; Formação de Professores.

\section{Katia Silene Ferreira de Mello-Paiva}

Professora Mestre do Departamento de Códigos

e Linguagens do IFG - Instituto Federal de

Educação, Ciência e Tecnologia de Goiás;

Goiânia; Goiás; Brasil.

katiapaiva2009@gmail.com

Abstract: This article discusses the digital literacy process of teachers of English as a foreign language who participated in a certified teacher education course. The paper also discusses literacy and digital literacy (BUZATO, 2001, 2006; SOARES, 2002, 2009; WARSCHAUER, 2011). The data analysis consisted of examining questionnaires, participants' productions as well as the group instructor's perceptions. Results revealed that experience with digital literacy occurred naturally, that is, not pre-established, it was frequent, via input and output and intensely collaborative. It was also noteworthy that the digital and virtual-based innovative classes triggered change of habits in terms of technological and organizational levels.

Key words: Literacy; Digital Literacy; Teacher Education. 



\section{Introdução}

Este artigo tem como objetivo discutir aspectos referentes ao letramento digital de um grupo de professores/as de língua estrangeira-inglês participantes de um curso de formacão continuada oferecido em 2013 em Goiás. Mais especificamente, o estudo busca identificar em que medida o letramento eletrônico (WARSCHAUER, 2011) é promovido nesse grupo mesmo que tal tema tenha sido abordado incidentalmente.

O curso foi implementado como parte da Rede Nacional de Formação Continuada de Professores/as da Educação Básica do Ministério da Educação e Cultura (MEC) cuja meta é a implementação de políticas regionais que visem a formação continuada de professores de inglês da educação básica pública.

Inicialmente, apresentamos algumas informações sobre a criação da Rede, sobre o curso de formação continuada oferecido em Goiás, bem como sobre sua organização e desenvolvimento, focalizando, em particular, um entre os 11 grupos distribuídos nos vários polos no estado. Em seguida, tratamos dos temas letramento e letramento digital com base em autores como Buzato, (2001, 2006), Soares (2002, 2009) e Warschauer (2011). Na sequência, descrevemos os procedimentos metodológicos detalhando o tipo de estudo conduzido, o contexto e os instrumentos usados para a coleta e a geração dos dados bem como os procedimentos de análise. Logo após, apresentamos e discutimos aspectos referentes ao processo de letramento digital dos docentes por meio do uso de várias ferramentas tecnológicas. Para finalizar, fazemos algumas considerações sobre letramento digital e formação de professores. 
1 A Rede Nacional de Formação

Continuada de Professores e o Curso de Formação Continuada de Professores/ as de Inglês como Língua Estrangeira/ Adicional

A Rede Nacional de Formação Continuada de Professores, constituída em julho de 2004 pelo governo federal, tem a finalidade de contribuir com a qualidade do ensino básico por meio de melhorias na formação de professores e alunos (BRASIL, 2006). Na proposta da Rede, o MEC oferece suporte técnico e financeiro e tem o papel de coordenar o desenvolvimento do programa por meio da Secretaria de Educação Básica (SEB). Participam também os Centros de Pesquisa e Desenvolvimento da Educação e os sistemas de ensino público. Tal rede não é a primeira política pública a incentivar ações de desenvolvimento profissional no campo educacional brasileiro (OLIVEIRA; PESSOA, 2013). No entanto, a iniciativa de incluir as línguas estrangeiras/adicionais é inédita no cenário nacional, segundo as autoras.

A partir da promulgação da Portaria 1.328/MEC, de 23 de setembro de 2011, que instituiu a Rede Nacional de Formação Continuada dos Profissionais do Magistério da Educação Básica Pública (BRASIL, 2011), a SEB, por meio da Diretoria de Currículos e Educação Integral, promoveu discussões entre vários setores da sociedade, pertinentes ao ensino de inglês como língua estrangeira/ adicional, sobre como novas políticas públicas poderiam aprimorar a área. Como apresentado em Oliveira e Pessoa (2013), ao longo de 2011 e 2012, várias reuniões foram realizadas com o objetivo de discutir a oferta de ensino de língua estrangeira (inglês) nas escolas públicas do Brasil. No Encontro da Rede Nacional de Formação de Professores/as da Educação Básica: Línguas Estrangeiras/ Adicionais - Etapa Inglês, realizado em Brasília, nos dias 23 e 24 de agosto de 2012, o grupo de trabalho (GT) 
assessor composto por representantes das regiões sul, sudeste e do Distrito Federal foi ampliado e contou com representantes de instituições de ensino de outros estados e regiões brasileiras. No encontro, os/as professores/as participantes de 23 estados discutiram a proposta inicial elaborada pelo GT assessor para um Plano Nacional de Formação Continuada de Professores/as de Inglês e apontaram ações já realizadas localmente. As discussões centraram-se na importância da reflexão em torno dos propósitos do Plano Nacional, dentre eles, (a) o que se entende por aprender uma língua estrangeira/adicional na escola pública brasileira, (b) o papel das universidades no que se refere à formação inicial e continuada de professores/as, (c) sugestões sobre a estrutura da rede e seu modo de atuação, com sugestões para ações imediatas e em longo prazo, entre outros.

Oliveira e Pessoa (2013) relatam que, em Goiás, após o retorno da reunião de agosto, as ações para a constituição da rede estadual tiveram início com o envio de convite para colegas de várias instituições de ensino superior e básico, a realização de reuniões para explicitação do projeto e o contato com as redes municipal e estadual de educação em busca de parceria no desenvolvimento da proposta. Nesse ínterim, o projeto tramitou pelas várias instâncias da UFG e do MEC e o termo de cooperação, celebrado entre o Fundo Nacional de Desenvolvimento da Educação (FNDE) e a UFG, foi publicado no Diário Oficial em 19 de novembro de 2012.

O Curso de Formação Continuada de Professores/ as de Inglês como Língua Estrangeira/Adicional foi cadastrado como projeto de extensão com vigência prevista para o período de dezembro de 2012 a dezembro de 2013. O curso foi coordenado por uma das autoras deste artigo, professora da UFG, e contou ainda com outros/as 19 professores/as formadores/as oriundos de outras instituições de ensino goianas como o Instituto 
${ }^{1}$ Os temas foram Collaborative English language learning, English language and cultures, English learning with coursebooks, English language materials, English learning with new technologies, Spoken and written English, English across the curriculum, English through themes, Critical English learning, English language and literature, English through projects, Language for the classroom, Creative writing e Task-based English learning, English learning and citizenship, English through new literacies, Visual literacies and English language e World Englishes learning.
Federal de Goiás (IFG), o Instituto Federal Goiano (IF Goiano), a Universidade Estadual de Goiás (UEG) e ainda da Secretaria Estadual de Educação (SEE) e das Secretarias Municipais de Educação (SME) das várias cidades onde se localizavam os polos.

Inicialmente, o curso previa vagas para 500 participantes que teriam aulas em 10 polos localizados em diferente locais no Estado. No entanto, como salientado por Oliveira e Pessoa (2013), por questões de pouco tempo para divulgação do curso e pelo fato de os participantes não terem conseguido redução de carga horária ou liberação de parte de suas atividades para frequentar as aulas, bem como dificuldades com a língua estrangeira e a distância dos polos, somente 189 professores/as se inscreveram e iniciaram o curso e, desses, apenas 110 finalizaram os módulos ministrados nos meses de março a junho e de agosto a dezembro de 2013. Em relação aos módulos, cada formador/a escolheu 4 de um elenco de 18 temas propostos pelo GT assessor. ${ }^{1}$ O planejamento dos conteúdos e das atividades foi feito em dezembro/2012 e janeiro/2013 e apresentado em reuniões conjuntas posteriormente sendo que algumas/ ns formadoras/es optaram por trabalhar alguns temas comuns de forma colaborativa.

Os processos formativos foram ofertados, predominantemente, na modalidade presencial, e organizados em 4 módulos de 30 horas cada, com encontros semanais às sextas feiras, de 4 horas de duração. Esses processos compreenderam ferramentas de comunicação e interação online, grupos de discussão virtual bem como ferramentas digitais, conforme características e condições da região em foco. Buscouse, por meio dessa organização, o equilíbrio entre o eixo linguístico-discursivo e o eixo pedagógico, ambos sendo trabalhados de forma integrada. 


\section{Letramento, Letramento Digital e Formação de Professores}

Os termos letramento e letramento digital são vocábulos recentes na nossa língua. Soares (2009) explica o surgimento recente de 'letramento' afirmando que palavras novas surgem (ou dá-se novo sentidos a velhas palavras) sempre que novos acontecimentos ocorrem, quando uma nova ideia, um novo fato, um novo objeto surgem ou são inventados. No caso, 'letramento' surgiu em decorrência da necessidade de ampliar o conceito de alfabetização para que não designasse apenas o processo de domínio da tecnologia do ler e do escrever (habilidades de codificação e decodificação), mas também os usos dessas habilidades em práticas sociais em que escrever e ler são necessários. Foi a partir da segunda metade da década de 80 que o termo surgiu no cenário educacional brasileiro como uma versão para o português da palavra 'literacy', como esclarece Soares (2009). Nas palavras da autora,

[o] surgimento do termo literacy nessa época reflete certamente uma mudança histórica nas práticas sociais: novas demandas sociais pelo uso da leitura e da escrita exigiram uma nova palavra para designá-las. Consequentemente, um novo conceito foi criado. (SOARES, 2009, p.79)

Em relação ao conceito de letramento, Soares (2002) afirma que não há uma diversidade de conceitos, mas sim, uma diversidade na sua caracterização. Há autores como Kleiman (1995, 1998), citada em Soares (2002), para quem letramento são as práticas sociais de leitura e escrita e os eventos em que essas práticas são postas em ação, bem como as consequências delas sobre a sociedade. Outra caracterização apresentada por Tfouni(1995, citadaemSOARES, 2002)levaem contaoimpacto social da escrita conceituando letramento em comparação à alfabetização. Para ela, "enquanto a alfabetização ocupa-se da aquisição da escrita por um indivíduo, ou grupo de indivíduos, 
${ }^{2}$ Ribeiro (2012) afirma que o artigo de Soares (2002) foi o primeiro no cenário brasileiro a fazer referência ao termo. o letramento focaliza os aspectos sócio-históricos da aquisição de um sistema escrito por uma sociedade" (TFOUNI, 1995, p. 20, citada em SOARES, 2002, p. 144). Soares (2009, p. 39) considera e ultrapassa tais aspectos ao argumentar que letramento resulta da "ação de ensinar e aprender as práticas sociais de leitura e escrita", sendo "o estado ou condição que adquire um grupo social ou indivíduo como consequência de ter-se apropriado da escrita e de suas práticas sociais". Em suas palavras, letramento é

o estado ou condição de indivíduos ou de grupos sociais de sociedades letradas que exercem efetivamente as práticas sociais de leitura e de escrita, participam competentemente de eventos de letramento. $\mathrm{O}$ que esta concepção acrescenta às anteriormente citadas é o pressuposto de que indivíduos ou grupos sociais que dominam o uso da leitura e da escrita e, portanto, têm as habilidades e atitudes necessárias para uma participação ativa e competente em situações em que práticas de leitura e/ou de escrita têm uma função essencial, mantêm com os outros e com o mundo que os cerca formas de interação, atitudes, competências discursivas e cognitivas que lhes conferem um determinado e diferenciado estado ou condição de inserção em uma sociedade letrada. (SOARES, 2002, p. 145, ênfase no original)

Reconhecendo a inserção cada dia maior das tecnologias de comunicação eletrônica e da escrita digital sobre as culturas de letramento tipográfico típicas da escrita e leitura no papel, Soares (2002) traz uma discussão sobre espaços de escrita e mecanismos de produção, reprodução e difusão da escrita e utiliza, pela primeira vez, o termo 'letramento digital'. ${ }^{2}$ Para ela, a escrita na tela, as práticas e usos da escrita contemporânea, o (hiper)texto produzido, as relações entre escritor e leitor, entre escritor e texto e entre leitor e texto acarretam mudanças e consequências sociais, cognitivas e discursivas e configuram, dessa forma, um letramento digital que vem a ser 
um certo estado ou condição que adquirem os que se apropriam da nova tecnologia digital e que exercem práticas de leitura e de escrita na tela, diferente do estado ou condição- do letramento dos que exercem práticas de leitura e de escrita no papel. (SOARES, 2002, p. 151, ênfase no original)

De fato, o letramento digital pressupõe práticas de leitura e de escrita distintas das formas tradicionais de letramento e alfabetização uma vez que o texto da tela é multimodal (possui texto, som, imagem e animação) e o hipertexto possibilita leitura e escrita não-lineares. Podemos entender o letramento digital, assim como Braga (2007) como uma ampliação do escopo do letramento baseado na cultura do papel no sentido de que as práticas letradas ocorrem no contexto digital.

Na área específica do ensino de línguas estrangeiras, Warschauer (2011) utiliza o termo genérico 'letramento eletrônico' para designar e englobar um conjunto de letramentos fundamentais e necessários para o uso eficaz das NTICs, a saber: o letramento computacional ou letramento por meio do computador, o letramento informacional, o letramento multimidiático e o letramento para a comunicação mediada por computador. Estes novos letramentos decorrem, em parte, das características dos recursos tecnológicos do computador e também do contexto social mais amplo no qual os computadores são usados (WARSCHAUER, 2011).

O letramento computacional ou por meio do computador refere-se à capacidade de realizar ações como ligar, desligar e utilizar o computador para operar programas simples, abrir, salvar e editar documentos, fazer upload download de arquivos e usar ferramentas de navegação na internet. O letramento informacional refere-se à gestão de grandes quantidades de informação tendo a capacidade de selecionar as informações 
necessárias, analisá-las e, sobretudo, utilizá-las de forma eficaz. O letramento multimidiático diz respeito à capacidade de compreender, utilizar e produzir conteúdos multimídia que incluem, entre outros, recursos semióticos, textos digitalizados, sons e vídeo. Por fim, o letramento para comunicação mediada por computador engloba a habilidade para gerenciar as comunicações on-line (e-mail, chat, e vídeo conferência) de uma forma eficaz que inclui seguir as regras sociais da comunicação on-line.

É importante destacar que estamos cientes da pluralidade do termo, dos múltiplos significados e variedades de letramento tendo em vista as condições de determinado momento sócio-histórico-cultural. E ainda das distinções entre letramento básico e crítico, adequado e inadequado, funcional e integral, geral e especializado, domesticador e libertador, descritivo e avaliativo (SOARES, 2009) e outras qualificações pertencentes ao que tem sido referido, mais recentemente, como novos letramentos ou multiletramentos. No entanto, dados os limites e objetivos deste texto, enfatizamos que tais aspectos não serão discutidos. Trataremos, pois, das práticas de letramento digital experienciadas incidentalmente no curso de formação continuada mencionado, pois, conforme Buzato (2001, p. 182), acreditamos que "é necessário que o professor responda de maneira pedagogicamente apropriada à inserção do computador na sua prática”. Concordamos com o autor que "a aquisição do letramento eletrônico depende da exposição do indivíduo à práticas coletivas/tutoriais em que a escrita mediada por computadores é significativa" (BUZATO, 2006, p. 86) e, ainda, que devemos "integrar o novo com o que já temos/sabemos, a partir do que já temos/sabemos, transformando esse conjunto de práticas, habilidades e significados da mesma forma como novos letramentos transformam os seus precursores" (BUZATO, 2006, p. 10). 


\section{Metodologia}

Os dados utilizados neste artigo foram obtidos a partir do corpus de uma pesquisa maior, de caráter etnográfico (ERICKSON, 1986), que engloba todos os grupos dos 10 polos durante os 9 meses de duração do curso. Por ser uma instância entre os demais e por focalizarmos as especificidades de um grupo em particular, a presente pesquisa caracteriza-se como um estudo de caso (LÜDKE; ANDRÉ, 1986). A preocupação central do realizador deste tipo de estudo é examinar, de forma aprofundada e exaustiva, uma "unidade entre um sistema mais amplo" (LÜDKE; ANDRÉ, 1986, p. 17) de forma que se possa revelar "a multiplicidade de dimensões presentes numa determinada situação ou problema, focalizando-o como um todo." (LÜDKE; ANDRÉ, 1986, p. 19).

O contexto do estudo compreende um entre os 11 grupos dos 10 polos localizados em diferentes regiões do estado. Além da própria formadora, professora da turma, consentiram em participar do estudo, assinando o termo de consentimento livre e esclarecido, 9 mulheres e 1 homem com média de idade de 40 anos e com experiência na área de ensino de língua inglesa que variava de 1 a 14 anos. Todos ministravam aulas em escolas da rede estadual no ensino fundamental e/ou médio, embora duas participantes estivessem atuando no Núcleo de Tecnologia Educacional (NTE) na ocasião do estudo. O nível de desenvolvimento de todas as participantes ${ }^{3}$ na língua inglesa foi considerado básico pela formadora, exceto por uma que era pré-intermediário. Tal nível condiz parcialmente com a autoavaliação delas feita em relação aos aspectos de leitura (L), compreensão oral (CO), produção oral $(\mathrm{PO})$ e produção escrita $(\mathrm{PE})$. A tabela a seguir sintetiza as informações sobre cada membro do grupo cujos nomes são fictícios:
${ }^{3}$ Adotaremos o gênero feminino, desse ponto em diante, para nos referirmos aos professores do estudo uma vez que neste grupo houve somente um homem entre os docentes participantes. 


\begin{tabular}{|c|c|c|c|c|c|c|c|c|c|c|}
\hline \multirow[t]{2}{*}{ Participante } & \multirow[t]{2}{*}{ Sexo } & \multirow[t]{2}{*}{ Idade } & \multirow[t]{2}{*}{ Formação } & \multirow{2}{*}{$\begin{array}{c}\text { Contexto } \\
\text { de } \\
\text { atuação }\end{array}$} & \multirow{2}{*}{$\begin{array}{c}N^{\circ} . \\
\text { módulos } \\
\text { concluídos }\end{array}$} & \multirow{2}{*}{$\begin{array}{c}\text { Tempo } \\
\text { de } \\
\text { atuação }\end{array}$} & \multicolumn{4}{|c|}{$\begin{array}{c}\text { Nível de } \\
\text { conhecimento na } \\
\text { língua inglesa }\end{array}$} \\
\hline & & & & & & & L & $\mathrm{CO}$ & PO & PE \\
\hline Ana Lara & Fem. & 39 & \begin{tabular}{|c|} 
Letras \\
Port.-Inglês
\end{tabular} & $\begin{array}{c}\text { Fora de } \\
\text { sala }\end{array}$ & 4 & 10 anos & B & B & $\mathrm{F}$ & $\mathrm{F}$ \\
\hline Divina & Fem. & 57 & \begin{tabular}{|c|} 
Letras \\
Port.-Inglês
\end{tabular} & $\begin{array}{l}\text { Ensino } \\
\text { Médio }\end{array}$ & 4 & 20 anos & ${ }^{\star} 0$ & 0 & $B$ & 0 \\
\hline Dinair & Fem. & 45 & Pedagogia & $\begin{array}{l}\text { Ensino } \\
\text { Fund. e } \\
\text { Médio }\end{array}$ & 4 & 3 anos & 0 & B & $\mathrm{R}$ & R \\
\hline Fernando & Masc & 36 & $\begin{array}{c}\text { Letras } \\
\text { Port.-Inglês }\end{array}$ & $\begin{array}{l}\text { Ensino } \\
\text { Fund. e } \\
\text { Médio }\end{array}$ & 3 & 3 anos & B & B & $B$ & B \\
\hline Isabela & Fem. & 38 & Pedagogia & $\begin{array}{l}\text { Ensino } \\
\text { Fund. }\end{array}$ & 2 & 1 ano & $\mathrm{F}$ & $R$ & $\mathrm{R}$ & $\mathrm{R}$ \\
\hline Madalena & Fem. & 30 & \begin{tabular}{|c|} 
Letras \\
Port.-Inglês \\
\end{tabular} & $\begin{array}{l}\text { Ensino } \\
\text { Fund. }\end{array}$ & 4 & $\begin{array}{c}5,5 \\
\text { anos } \\
\end{array}$ & $\mathrm{F}$ & $\mathrm{R}$ & $\mathrm{F}$ & $F$ \\
\hline Silvina & Fem. & 39 & \begin{tabular}{c|} 
Letras \\
Port.-Inglês
\end{tabular} & $\begin{array}{l}\text { Ensino } \\
\text { Fund. }\end{array}$ & 4 & 14 anos & 0 & $\mathrm{R}$ & B & B \\
\hline Serva & Fem. & 44 & \begin{tabular}{c|} 
Letras \\
Port.-Inglês
\end{tabular} & $\begin{array}{l}\text { Ensino } \\
\text { Fund. }\end{array}$ & 4 & 5 anos & B & B & B & $\mathrm{R}$ \\
\hline Reisla & Fem. & 37 & \begin{tabular}{c|} 
Letras \\
Port.-Inglês \\
\end{tabular} & $\begin{array}{l}\text { Fora de } \\
\text { sala }\end{array}$ & 4 & 5 anos & R & $\mathrm{R}$ & $\mathrm{R}$ & R \\
\hline Rute & Fem. & 43 & \begin{tabular}{c|} 
Letras \\
Port.-Inglês
\end{tabular} & $\begin{array}{l}\text { Ensino } \\
\text { Fund. }\end{array}$ & 4 & 13 anos & $\mathrm{R}$ & $\mathrm{R}$ & $\mathrm{R}$ & $\mathrm{R}$ \\
\hline
\end{tabular}

* O - ótimo, B - bom, $\mathrm{R}$ - razoável, F - fraco.

A formadora incorporou práticas de letramento digital e discussões relacionadas à formação de professores em todos os 4 módulos ministrados. Embora houvesse um módulo exclusivo abordando a questão das NTICs, a formadora não o elegeu, especificamente, entre os 4 que iria trabalhar por acreditar que o letramento digital perpassaria quaisquer dos módulos selecionados ocorrendo, assim, de forma incidental. Os módulos selecionados foram os seguintes: Creative Writing, Learning English with Textbooks, Spoken and Written Language e Task-Based Language Learning (TBLL).

Os instrumentos de coleta e geração de dados incluíram as produções das participantes ao longo do curso (portfólios e histórias digitais). Foram também analisados os documentos da formadora - programas de curso, conteúdo programático, planos de aula e as respostas registradas no questionário aberto aplicado ao fim de cada módulo. A análise consistiu no exame exaustivo desses dados com o objetivo de buscar padrões e identificar em que medida as práticas secundárias de uso das NTICs 
promoveram o letramento eletrônico (WARSCHAUER, 2011) nesse grupo.

\section{Resultados e Discussão - Instrução pedagógica mediada por recursos digitais e virtuais variados}

Como mencionado no item 3 do artigo, parte do corpus analisado refere-se ao estudo detalhado dos documentos da formadora - programas de curso, conteúdo programático, planos de aula e as respostas ao questionário. Os resultados desta análise mostram o uso frequente e contínuo de recursos tecnológicos em suas aulas como os excertos, a seguir, atestam:

[1] Outro ponto forte foi o contínuo uso de tecnologia. Eu insisti em receber TODAS as produções via email ou google doc e fornecia TODOS OS feedbacks via revisão de texto do WORD (track changes). Então tiveram a oportunidade de melhorar e lidar mais com as tecnologias oferecidas no word. (Questionário da Formadora - Módulo 2 - Learning English with Coursebooks - ênfase no original)

[2] Tenho que reconhecer que foi bom, elas amaram a digital story bem como o ato de contar e recontar estória. (...)

Daí comecei a soltar, fizeram atividades no Bookr, no Power Point e no Movie Maker. Buscaram inglês no Google Translator e mandaram arquivos pra mim pelo Google Docs ou Google Power Point.

Foi mesmo uma enxurrada de novas tecnologias misturadas com inglês. Mas ainda, assim, mais escrita do que fala. Pq muitas escreveram sua estória em Português pra depois passar para inglês. Tudo bem.... essas morreram para aprender lidar com o track changes do Word, pq não dei mole, corrigia e elas tinham que revisar. (Questionário da Formadora - Módulo 3 - Spoken and Written Language) 
O interesse em executar seus planos de ensino, cujo material didático foi todo confeccionado via recursos digitais, perpassava naturalmente a execução das aulas. Seu conteúdo programático descreve o uso constante de equipamentos tecnológicos como data show e notebook, bem como a incorporação de conteúdos multimídia para promover discussão de conceitos metodológicos como, por exemplo, Youtube vídeos, aula mediada por vídeo conferência, apresentação em Power Point com inclusão de áudio, clipboard, hyperlink, animações e transições de slides variados. Houve ainda o uso de programas digitais e virtuais, tais como, Movie Maker com áudio, arquivo próprio de fotos digitais, inserção de narração e fundo musical, promoção do uso da ferramenta Bookr (http:// www.pimpampum.net/bookr/) para a confecção da história digital e ainda a utilização exaustiva do recurso Google Docs.

A função principal do Google Docs era substituir a lousa, uma vez que o arquivo produzido poderia ser compartilhado com as participantes simultaneamente. Assim, elas escreviam junto com a professora, compartilhando ideias e, posteriormente, salvavam o documento em seus arquivos ao final de cada encontro. Desse modo, as participantes deixavam de copiar os conteúdos como estavam acostumadas a fazer e asseguravam a obtenção do "quadro negro" de todas as aulas e o arquivavam para uso posterior. Como apontado por Soares (2002), essa prática contemporânea de escrita na tela configura o letramento digital.

Além dos recursos mencionados, a formadora também fez uso constante da ferramenta de revisão de texto (Track changes) do programa Word na sua pedagogia de feedback. A ferramenta era utilizada nas produções escritas das participantes, uma vez que essas eram entregues a ela somente via email ou Google Doc, como mostrado no excerto 2. Dentre tais produções, 
destaca-se o portfólio digital (Anexo A) - projeto final de cada módulo - cujos dados são discutidos mais adiante, com mais especificidade.

A análise das produções das participantes ao longo do curso (portfólio e história digital) mostra que, mesmo não sendo o foco de quaisquer dos módulos, as práticas de letramento digital utilizadas pela formadora e experienciadas pelas participantes contribuíram para o desenvolvimento do seu letramento eletrônico (WARSCHAUER, 2011).

É importante salientar que os resultados da análise mostram que esse processo de desenvolvimento ocorreu de maneira individual e também colaborativa. Individual porque as participantes apresentavam níveis de letramento eletrônico variados no início do curso. Aquelas que já demonstravam facilidade no manuseio do computador (Letramento Computacional), por exemplo, incorporaram os recursos tecnológicos inovadores em suas produções com mais frequência e sofisticação como demonstrado pelas participantes Madalena e Ana Lara. Ambas davam assistência tecnológica à formadora frequentemente durante as aulas com o manuseio dos equipamentos tecnológicos e, logo, começaram a trazer seus notebooks para as aulas.

A participante Madalena fez uso de recursos tecnológicos diferenciados das demais nas suas produções demonstrando, claramente, o letramento multimidiático (WARSCHAUER, 2011). Exemplo disso foi o caráter multimodal (SOARES, 2002) da sua história digital que possui texto, som, imagens e animações. Diferentemente das demais participantes que escolheram o Power Point devido a sua relativa facilidade de manuseio, Madalena utilizou o programa Movie Maker para apresentar sua digital story, cujo tema foi a construção de sua própria casa. Ela incorporou fundo musical relacionado ao tema escolhido - A Casa de Toquinho e Vinicius de Moraes, 
bem como a gravação/narração de sua fala, em inglês, descrevendo a produção. A participante usou ainda recursos variados de animação e transição de slides e também adicionou o recurso de close caption para cada slide. Finalmente, é importante ressaltar que essa participante criou sua própria história baseada na coleção de fotos digitais de arquivo próprio ainda que esta tenha sido sua primeira experiência em criar uma digital story demonstrando, assim, uma ampliação do escopo do letramento baseado na cultura do papel (SOARES, 2002; BRAGA, 2007).

Os resultados desta análise em específico mostram ainda que o ambiente colaborativo permeou significativamente o curso nos níveis tecnológico e linguístico. Como mencionado anteriormente, o processo de desenvolvimento do letramento eletrônico (WARSCHAUER, 2011) ocorreu também de forma colaborativa. Ana Lara, assim como Madalena, apresentou recursos sofisticados na apresentação de sua história digital, porém, sua pouca proficiência na língua inglesa foi um obstáculo para a realização do projeto. Entretanto, a realização das tarefas feitas em pares e grupos minimizou as dificuldades diante desse obstáculo representado pela língua estrangeira/adicional. A participante Ana Lara construiu sua história digital em conjunto com a participante Divina que tem o nível de proficiência linguística mais elevado, porém não apresentava plena familiarização com o letramento computacional (WARSCHAUER, 2011) ou com os demais.

Diante do resultado de suas histórias digitais, percebemos que o fato de terem sido expostas às práticas escritas coletivas, em que a escrita mediada por recursos computacionais são significativas (BUZATO, 2006), contribuiu para o aprimoramento de ambos os aspectos linguístico e tecnológico dessas participantes. Embora tenham sido construídas colaborativamente, as histórias 
digitais de Divina e Ana Lara possuem temas e recursos tecnológicos diferenciados e elas conseguiram concluir o projeto com sucesso independentemente de seus limites com a língua alvo ou com o letramento eletrônico.

Em relação à análise mais detalhada das produções escritas das participantes, mas especificamente do portfólio digital, é importante enfatizar que sua criação aconteceu de maneira natural, ou seja, não préestabelecida. À medida que os trabalhos começaram a ser enviados on-line, que percebemos a não rejeição e a adaptação a tal pedido, surgiu a ideia de transformar o portfólio impresso, pré-estabelecido no plano do curso, em um portfólio digital.

A análise do processo de construção desse portfólio revela o desenvolvimento do letramento eletrônico nos níveis computacional, multimidiático e informacional (WARSCHAUER, 2011). Em particular, focamos essa parte da análise no uso do recurso chamado Track changes do programa Word da Microsoft Office. Esse recurso digital foi usado constantemente pela formadora em seu feedback às produções escritas das participantes. As correções, comentários e sugestões de mudanças eram feitas por meio desse recurso. O Track changes (revisão de texto) é, portanto, uma ferramenta que leva as práticas de leitura e escrita para a tela oferecendo, dessa forma, oportunidade de letramento digital (SOARES, 2002).

Observamos que, inicialmente, a falta de familiaridade da maioria das participantes com o Track changes tornou o processo de letramento computacional e informacional mais demorado. Apesar de elas apresentarem facilidade na operacionalização de várias ações como utilizar programas simples, abrir e salvar documentos, baixar e enviar arquivos por email, durante o período inicial do curso as participantes não tiraram aproveito das correções por não saberem manusear a ferramenta ao receber o feedback em suas produções 
escritas. O processo de aprendizagem de manuseio do Track changes foi relativamente lento, entretanto, uma vez entendido, se tornou uma prática durante o curso.

$\mathrm{Na}$ figura a seguir, há um screenshot de um feedback na primeira versão do portfólio do participante Fernando que mostra o uso do recurso Track changes.

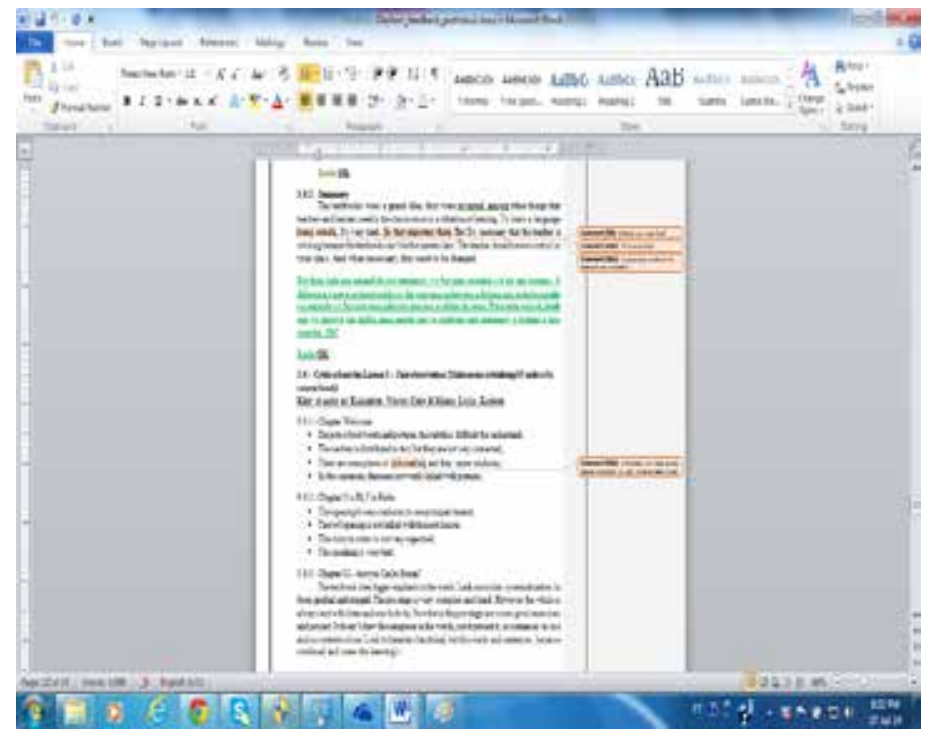

Figura 1. Exemplo de uso do recurso Track changes.

De forma geral, as modificações sugeridas nas produções eram acatadas muito tempo depois de terem sido enviadas, quase ao término do primeiro módulo. Esse fato, em nossa análise, se deu devido à limitação dos participantes em lidar com o novo recurso digital no início no curso. Mediante tal dificuldade, a formadora executou práticas coletivas/tutoriais junto às participantes, integrando o novo ao que já sabiam (BUZATO, 2006).

Outro aspecto digno de menção diz respeito às ações da formadora que serviram de referência e até de modelo para as participantes (BUZATO, 2006). Podemos mencionar, por exemplo, que no início do curso somente a professora trazia seu notebook, porém com o uso intenso 
de recursos digitais, de compartilhamento de arquivos do Google doc, de propostas de atividades no programa Hot Potatoes , uso do Bookr e outros sendo projetados no data show, as participantes logo começaram a trazer notebooks e algumas compartilhavam a necessidade de adquirir o seu próprio aparelho e assim o fizeram, como foi o caso da participante Serva.

Finalizando, os resultados mostram desenvolvimento do letramento eletrônico em três categorias, a saber: (a) computacional, com o uso do Track changes por exemplo; (b) informacional, considerando a necessidade de gestão de grande quantidade de informações necessárias para a confecção do portfólio que foi organizado no final do curso; e (c) multimidiático, uma vez que as participantes executaram tarefas que promoveram o uso de recursos multimídias mais sofisticados e de programas de softwares como, por exemplo, os utilizados na digital story e na organização final do portfólio digital.

Percebemos também que o processo ocorreu de maneira individual, de acordo com o nível de letramento digital inicial de cada participante, e colaborativo, uma vez que as experiências tecnológicas foram realizadas por meio de interações em pares e/ou em grupos. Finalmente, vale salientar, que o processo de letramento digital aconteceu naturalmente, ou seja, não pré-estabelecido. As instruções relacionadas a essa área aconteceram incidentalmente à medida que as necessidades das participantes foram aparecendo, não necessariamente como opção de módulo de instrução como salientado.

\section{Consideracões Finais}

O presente estudo propõe algumas considerações que nos levam a refletir sobre práticas de letramento digital na área de formação de professores. Tais considerações
${ }^{4}$ Hot Potatoes é um programa de autoria gratuito que inclui aplicações diversas, possibilitando a criação de atividades online como: múltipla escolha, palavra cruzada, ordenar ou combinar colunas, reorganizar frases, preencher lacunas e outros. Veja http:// hotpot.uvic.ca/para maiores detalhes. 
estão relacionadas aos seguintes aspectos: (1) naturalidade do uso dessas práticas, (2) gradação e colaboração, (3) mudança de hábitos; e finalmente (4) necessidade de haver estudos empíricos na área de CALL (ComputerAssisted Language Learning).

Em primeiro lugar, o aspecto de naturalidade do uso dessas práticas tende a ocorrer, inicialmente, por meio das próprias acões do formador que se torna referência para os participantes (BUZATO, 2006). Observamos que as participantes mais interessadas em tecnologia e, posteriormente, as demais acabam por integrar as práticas observadas. Estamos cientes que há casos de rejeição a essa nova prática de aprendizado, porém não foi o caso desse grupo. Portanto, letramento digital não deve, necessáriamente, ser pré-estabelecido no plano de ensino, porém, uma vez que práticas de uso tecnológico são costumes do formador, elas passam a se tornar naturais em suas aulas e servem de referência para os participantes do curso de formação.

Em segundo lugar, o letramento eletrônico, seja referente a quaisquer daqueles apresentados por Warschauer (2011), tende a se desenvolver de maneira gradativa de acordo com o interesse do participante, por meio do processo individual de aprendizagem, bem como pelas ações pedagógicas via instrutor/formador. No entanto, práticas colaborativas de produção e negociação de tarefas tendem a acelerar o processo e despertar motivação, interesse, criatividade, sentimento de pertença (sense of ownership) (DAVIDSON; LYNCH, 2002) e, consequentemente, aprimoramento tecnológico.

Em terceiro lugar, o uso de recursos tecnológicos digitais em aulas de línguas não somente serve de referência para os alunos via instrutor/formador, como também tendem a provocar mudança de hábitos. Como mencionado, as participantes pareciam querer imitar a formadora e até mesmo possuir os mesmos aparelhos 
ou programas virtuais que ela usava em suas aulas. Além do mais, resultados deste estudo também mostram que, no âmbito organizacional, foi o estilo de organização da formadora que acabou prevalecendo nos arquivos dos participantes.

Enfim, há urgência em desenvolver ações na área de $C A L L$ no Brasil para que as autoridades sejam conscientizadas da necessidade de dar suporte não só financeiro às instituições no âmbito tecnológico, mas também no desenvolvimento do letramento digital dos docentes.

Para finalizar, houve, na verdade, um caos inicial penoso, porém saudável para todos os envolvidos no processo. Embora sentimentos de frustração tenham ocorrido, o desejo de superar obstáculos e vencer as limitações ficou evidente no decorrer e no final do curso uma vez que dos 14 participantes iniciais 8 concluíram os 4 módulos do curso com sucesso. 


\section{Referências}

BRAGA, D. B. Letramento na internet: o que mudou e como tais mudanças podem afetar a linguagem, o ensino e o acesso social. In: KLEIMAN, A. B.; CAVALCANTI, M. C. (Org.). Linguística Aplicada: suas faces e interfaces. Campinas, SP: Mercado de Letras, 2007. p. 181-198.

BRASIL. Ministério da Educação e Cultura. Secretaria de Educação Básica. Rede Nacional de Formação Continuada de Professores da Educação Básica: orientações gerais. Brasília: MEC, 2006.

BRASIL. Portaria 1.328/MEC, 23 de setembro de 2011, instituiu a Rede Nacional de Formação Continuada dos Profissionais do Magistério da Educação Básica Pública, MEC: 2011.

BUZATO, M. E. K. Letramentos digitais e formação de professores. In: III Congresso Ibero-Americano EducaRede. Educação e Internet: A Formação do Professor Autor.

São Paulo, 2006. Disponível em: <http://www.unilago.com. br/arquivosdst/24983MarceloBuzato\%20-\%20letramento\%20 digital\%20e\%20formacao\%20de\%20profs\%20@.pdf> Acesso em 27 jan. 2014.

\section{. O Letramento Eletrônico e o Uso do Computador}

no Ensino de Língua Estrangeira: contribuições para a formação de professores. Dissertação (Mestrado em Linguística Aplicada). Unicamp, Campinas, 2001. $188 \mathrm{f}$.

DAVIDSON, F.; LYNCH, B. Testcraft: a teacher's guide to writing and using language test specifications. Yale University Press: New Haven and London, 2002.

ERICKSON, F. Qualitative methods in research on teaching. In: WITTROCK, M. C. (Ed.) Handbook of Research on Teaching, Third Edition, New York: MacMillan, 1986. p. 119160. 
GASS, S. M.; SELINKER, L. Second language acquisition: an introductory course, 2nd ed. Mahwah, New Jersey: Lawrence Erlbaum Associates, 2001.

GRIFFEE, D. T. An Introduction to Second Language Research Methods: Design and Data. TESL-EJ Publications: Berkeley, California, USA, 2012.

LÜDKE, M.; ANDRÉ, M. E. D. A. Pesquisa em Educação: Abordagens Qualitativas. São Paulo: EPU, 1986.

OLIVEIRA, E. C. de; PESSOA, R. R. Rede Nacional de Formação Continuada de Professoras/es de Inglês como Língua Estrangeira/Adicional: projeto UFG. In: VEDIPE Encontro Estadual de Didática e Práticas de Ensino, 2013, Goiânia, Anais..., Universidade Federal de Goiás, 2013, p. 1-15.

RIBEIRO, M. H. Práticas de Letramento Digital na Formação de Professores: um desafio contemporâneo. Dissertação (Mestrado em Educação). Universidade Federal de Juiz de Fora, Juiz de Fora, 2012. $236 \mathrm{f}$.

SOARES, M. Novas práticas de leitura e escrita: letramento na cibercultura. Educação e Sociedade. Campinas, v. 23, n. 81, p. 143-160, 2002. Disponível em: < http://www.scielo.br/scielo. php?script=sci_arttext\&pid=S0101-73302002008100008> Acesso em: 28 out. 2013.

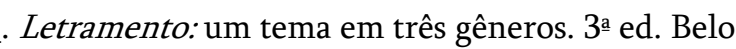
Horizonte: Autêntica, 2009.

WARSCHAUER, M. (no prelo). A literacy approach to the digital divide. In: PEREYRA, M. A. (Ed.), Las mulialfabetizaciones en el espacio digital. Malaga, Spain: Ediciones Aljibe. Disponível em: <http://www.gse.uci.edu/ person/warschauer_m/docs/lit-approach.pdf> Acesso em: 28 out. 2013. 


\section{Anexo A: links produçôes das participantes}

Digital story (link)

https://drive.google.com/file/

d/0B6W00SFgf7CDOEFQZ0w0cXBiTW8/edit?usp=sharing

Digital Portfolio (link)

https://drive.google.com/file/d/0B6W00SFgf7CDQkdyaV94Rz

VzOExEVXhHcElkbEtOQmxPd3FB/edit?usp=sharing

Tale $(\underline{\text { link }})$

https:/drive.google.com/file/

d/0B6W00SFgf7CDXzZjRjNISXU1THc/edit?usp=sharing

Recebido em 04/04/2014

Aceito para publicação em 30/07/2014 